\title{
A Reinvestigation of Crustal Thickness in the Tibetan Plateau Using Absolute Gravity, GPS and GRACE Data
}

\author{
Wenke Sun ${ }^{1,2, *}$, Qi Wang ${ }^{3}$, Hui $\mathrm{Li}^{3}$, Yong Wang ${ }^{4}$, and Shuhei Okubo ${ }^{2}$ \\ ${ }^{1}$ Key Laboratory of Computational Geodynamics, Graduate University of Chinese Academy of Sciences, China \\ ${ }^{2}$ Earthquake Research Institute, The University of Tokyo, Japan \\ ${ }^{3}$ Institute of Seismology, China Earthquake Administration, China \\ ${ }^{4}$ Institute of Geodesy and Geophysics, Chinese Academy of Sciences, China
}

Received 8 December 2009, accepted 7 June 2010

\begin{abstract}
The geodetic evidence of the uplift and crustal thickness of the Tibetan Plateau has been presented for the first time (Sun et al. 2009) using gravity and GPS observations. In this paper, we reinvestigate this tectonic deformation in more detail using GRACE data and taking the GIA effect into account. We first summarize the previous gravity and GPS observations and a local gravity network in the Dali County. The comparison between the surface absolute gravity and space GRACE gravity measurements shows that they are harmonic, agree well. Finally, we assume that the residual gravity change reflects material transport accompanying vertical movements on the crustal bottom; the crustal thickening rate is inferred as $1.9 \pm 1.4 \mathrm{~cm} \mathrm{yr}^{-1}$. As the crust thickens, the mass of a column of rock beneath the station decreases because mantle is displaced by crust, causing a reduction in gravity.
\end{abstract}

Key words: Gravity change, GPS measurement, Tibetan Plateau, Mass loss, Crustal thickness

Citation: Sun, W., Q. Wang, H. Li, Y. Wang, and S. Okubo, 2011: A reinvestigation of crustal thickness in the Tibetan Plateau using absolute gravity, GPS and GRACE data. Terr. Atmos. Ocean. Sci., 22, 109-119, doi: 10.3319/TAO.2010.06.07.01(TibXS)

\section{INTRODUCTION}

Beginning some fifty million years ago northward movement of the Indian subcontinent has continuously altered the shape of the Tibetan Plateau (Tapponnier et al. 2001). The high rate of seismicity along the Himalayas reflects a collision between India and Asia is still thrusting the Tibetan Plateau upward. The huge mass of Asia to the west and north restricts the northward movement of the plateau's crustal material. Consequently, northward movement along deep-seated thrust faults is transferred laterally to the east and southeast roughly along the east-west trending strike-slip faults. The nearly north-south trending strikeslip faulting in eastern Tibet and western Sichuan and the rotation of S.E. Asia southeastward into the South China Sea can be interpreted as eastward and southeastward extrusion of Tibetan crustal blocks. The horizontal displacements obtained by GPS measurements in China show that crustal shortening accommodates most by the penetration of Indian

\footnotetext{
* Corresponding author

E-mail:sunw@gucas.ac.cn
}

plate into Eurasia plate (Wang et al. 2001). A continuum deformation appears to characterize the active tectonics of the Tibetan Plateau. However, this continuum deformation is apparently confined to the plateau itself and is absorbed by crustal thickening thus causing vertical crustal movement, i.e., elevated topography of the Tibetan Plateau and a subsided crustal bottom at depth. The seismological tomographic evidence showing that the lithospheric crust under south Tibet has doubled to $80 \mathrm{~km}$ thickness (Chen and Yang 2004) and supports this hypothesis. Many of the large earthquakes, including the 2008 Wenchuan earthquake (M 8.0), were located on the Red River and are characterized by dip slip faults.

Many national (the State Seismology Bureau, the Ministry of Geology and the Institute of the Geology of the Chinese Academy of Sciences) and international cooperative observations and studies were carried out in the western Yunnan and Tibetan regions, such as the absolute gravity measurements made at Kunming, Dali and Lhasa stations since 1990, under Sino-Finnish, Sino-German and Sino- 
Japan joint observations (Mäkinen et al. 1993; Wang et al. 2004; Zhang and Wang 2005; Takemoto et al. 2006). To investigate the tectonic structure and seismic activities at the edge area of the Tibetan Plateau through gravity changes caused by the movement of the large scale fault systems, a local absolute gravity network was established in 2005 in Dali county of Yunnan province, in a joint collaboration of Earthquake Research Institute (ERI), the University of Tokyo, the Institute of Seismology (IoS) and Yunnan Seismological Bureau, China Earthquake Administrations. The first observation was performed in 2005, and repeated in 2007. The observed gravity values serve as a standard for future measurements and can be used to other tectonic studies like the crustal thickening to be discussed below.

Based on all the previous observations, Sun et al. (2009) presented for the first time the geodetic evidence of the uplift and crustal thickness of the Tibetan Plateau, combining absolute gravity and GPS data at three stations: Lhasa, Kunming and Dali. Removing the contribution of surface vertical displacement, gravity values on the deformed earth surface are then transformed to a fixed point. Thereby, residual gravity changes are considered to reflect the interior mass distribution, and are attributed to lowering Moho at depth by crustal thickening. The thickening rate is inferred as $2.3 \pm 1.3 \mathrm{~cm} \mathrm{yr}^{-1}$. However, there are still some problems deserving further discussions.

In this paper, we further discuss the tectonic deformation of the Tibetan Plateau, including GRACE data and GIA (Glacier Isostatic Adjustment) effect into account. We first summarize the gravity and GPS observations at the three stations and the above mentioned local gravity network in
Dali County. The local gravity network shows, as an example among other gravity observation projects, how absolute gravity measurement was made, and how accurate the absolute gravity is measured. Then we transform the observed gravity from deformed surface to space-fixed point using GPS observed vertical crustal displacement, corrected by the surface denudation. The observed gravity change rate is also compared with the GRACE data, and results show that the absolute and space gravity measurement agree well. The gravity change rate is further corrected by the GIA effect caused by the LGM (last glacial maximum). Then the residual gravity change is assumed to reflect material transport accompanying vertical movements on the crustal bottom. As the crust thickens, the mass of a column of rock beneath the station decreases because mantle is displaced by crust, causing a reduction in gravity.

\section{THREE ABSOLUTE GRAVITY AND GPS OBSER- VATION STATIONS AND A GRAVITY NETWORK}

To interpret gravity change rate, GPS and gravity measurements are necessary. Within the entire Tibetan Plateau, we specifically examine data obtained at three unique stations, Lhasa $\left(29.66^{\circ} \mathrm{N}, 91.10^{\circ} \mathrm{E}\right)$, Kunming $\left(25.13^{\circ} \mathrm{N}\right.$, $\left.102.76^{\circ} \mathrm{E}\right)$, and Dali $\left(25.61^{\circ} \mathrm{N}, 100.25^{\circ} \mathrm{E}\right)$ where two types of data are available (Fig. 1a). These stations are managed as part of the Chinese National Geodetic Observation Network. Lhasa Station has two observation points; both belong to the Surveying and Mapping Bureau of Tibet, but are located respectively within the capital city of Lhasa (3643 and $3645 \mathrm{~m}$ a.s.l. separated by ca. $800 \mathrm{~m}$ ) in the southern (a)

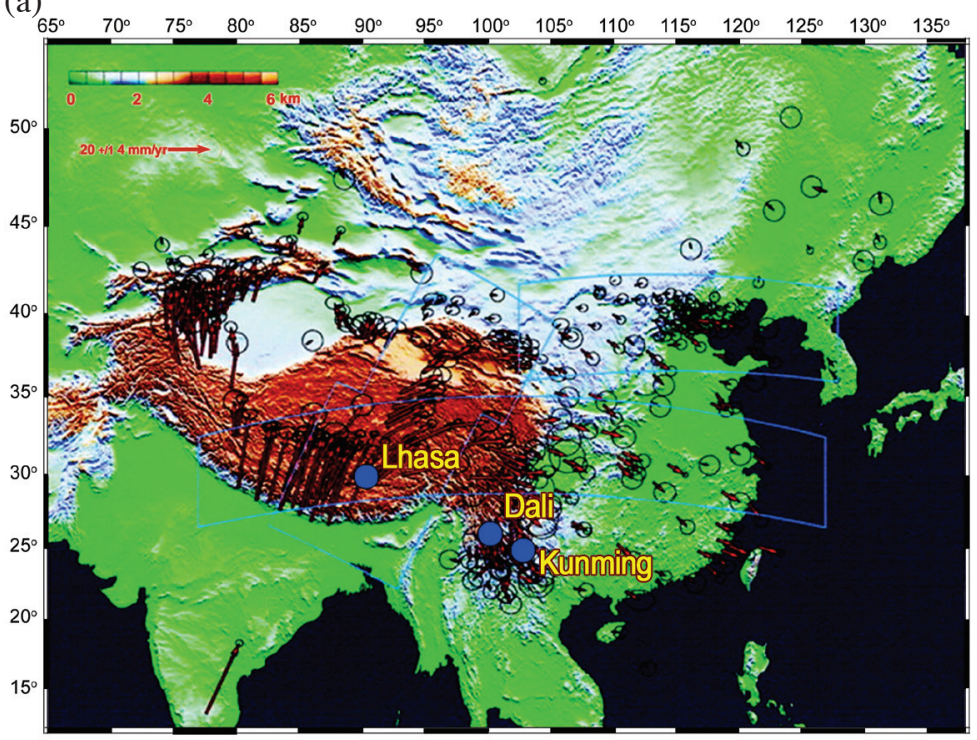

(b)

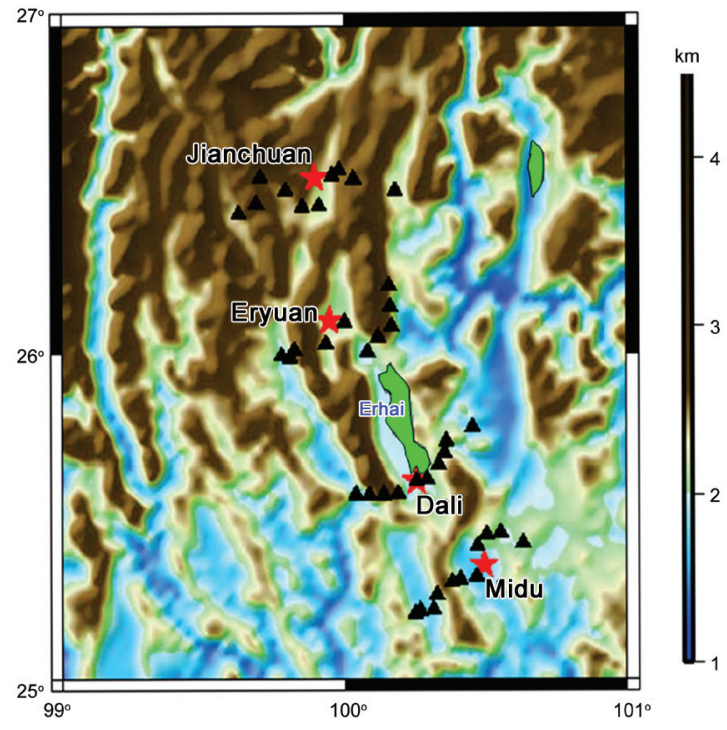

Fig. 1. (a) Location of the absolute gravity and GPS stations (Lhasa, Dali and Kunming, shown as blue circles) and the local gravity network in the Dali county, with background of horizontal displacement filed (after Wang et al. 2001); and (b) distributions of the absolute/relative gravity stations in the local gravity network. Red star stands for absolute gravity stations; Black triangle means relative gravity observation points. 
plateau. The GPS station is $2000 \mathrm{~km}$ away from the gravity stations. Because of their proximity, they can be assumed to have the same crustal deformation properties and might be considered as one station. The other two stations (Kunming seismic station and Dali seismic station) are located in southeastern Tibet, with slightly lower respective elevations of 1952 and 1958 m. The GPS station in Kunming is located about $8900 \mathrm{~m}$ south of the gravity station; the GPS station in Dali is located at the same site as the gravity station. At the three stations, both GPS and gravity measurements have been performed for a decade or more. Continuous GPS observations have been made from 1995 or 1998 to the present. Absolute and relative gravity measurements have been carried out regularly since the early 1990s.

As shown in Fig. 1a, the western Yunnan region is undergoing an average velocity of 6 to $11 \mathrm{~mm} \mathrm{yr}^{-1}$ with respect to stable Eurasia oriented toward an azimuth of N 100 $-130^{\circ} \mathrm{E}$. Since the entire South China block behaves as an almost rigid block (Wang et al. 2001), the Tibetan plateau undergoes substantial internal shortening, with the direction of maximum shortening in $\mathrm{N} 21^{\circ} \mathrm{E}$, with about $38 \mathrm{~mm} \mathrm{yr}^{-1}$ convergence rate between the Indian plate and the rigid Alashan block north of the Qilian Shan. The velocity gradient is strikingly linear except for a high-velocity gradient across the Himalaya at the southern margin of the plateau. The average convergence strain rate in this direction is about $2 \times 10^{-8}$ per year. More than $30 \%$ of the total India-Eurasia convergence is absorbed by internal shortening of the plateau. Thus, continuum rather than block-like deformation appears to characterize present-day tectonics of the Tibetan Plateau. This continuum deformation, however, seems to be limited within the plateau itself. Rigid block-like motion appears to characterize deformation of the regions to the north, northeast, and east, and there are zones of concentrated contraction at both the north and south margins of the plateau. Therefore, it is interesting to observe how gravity behaves in such a contraction areas. For this purpose, in addition to the existing stations of Lhasa, Kunming and Dali, a local gravity network was designed in 2005 in the south margin of the Tibet plateau, or western Yunnan province by a joint observation project of the ERI and IoS.

The earliest absolute gravity measurements were made at the three stations in 1990; they were repeated in 1992 and 1995, respectively, under Sino-Finnish and Sino-German joint observations (Mäkinen et al. 1993). For those studies, JILAG-3 and JILAG-5 absolute gravity meters were used. Observations at each station were usually carried out during 1 - 2 days. The measurements comprised 10 - 20 sets; each set included 100 free-fall drops. With the standard deviation for each set was about 10 - $60 \mu \mathrm{gal}$; the standard deviation of the total set gravity was about 1 - $5 \mu$ gal. Since 1996, these stations have been revisited by the Institute of Geodesy and Geophysics of the Chinese Academy of Sciences, China, with their absolute gravimeter (FG5\#112; Micro-g Solu- tions Inc.), by a joint observation of China and the United States in 1998 using a FG5\#107, and by a joint observation of China and Japan in 2004 using FG5\#210 (Takemoto et al. 2006). The measurements at each station comprised 24 - 28 sets within $24 \mathrm{~h}$; each set included 100 free-fall drops, with the standard deviation for each set was about $7-12 \mu \mathrm{gal}$. The standard deviation of the total gravity set was about 1 $2 \mu \mathrm{gal}$. The gravity gradient at each station was measured using LaCoste-Romberg G type relative gravimeters (Zhang et al. 2001; Wand and Zhang 2004; Wang et al. 2004; Zhang and Wang 2005). In 2005, the FG5\#212 was reinstalled at the Dali station based on a cooperative project between ERI, IOS and the Yunnan Seismological Bureau. This project created a local gravity network containing four absolute stations and 40 relative observation points (Fig. 1b). The four absolute stations Midu, Dali, Eryuan and Jianchuan are located in Dali county of Yunnan province. The distance between any two neighbor stations is about $50-70 \mathrm{~km}$. The first measurement was carried out at the four stations in September 2005 using Micro-g Solutions FG5\#212 absolute gravimeter (owned by ERI), and reoccupied in December 2007 using FG5\#232 (owned by IoS). At the same time, taking each absolute gravity station as a center, four relative gravity profiles were designed and measured by 5 Locoste \& Romberg G-type gravimeters \#581, \#793, \#854, \#1003 and \#1132, with 10 stations in each profile. In the following, we present the first measurement performed in 2005 to demonstrate surveying in detail of observation, data processing and physical corrections.

\subsection{Measurement of the Gravity Gradient}

Gravity gradients at the four absolute gravity stations were measured with relative gravimeters LCR-G581 and LCR-G854. Six-return measurements were performed by each meter for each station. Final gradients were obtained by taking mean of the results obtained by the two meters. The gravity difference, height and final gravity gradient are listed in Table 1. The accuracy of the gradient results was

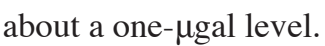

\subsection{Absolute Gravity Measurements and Results}

Absolute gravity was observed at the four stations from 3 to 13 September 2005, about two full days for each station, plus the transport time. Post data processing was performed using "g" software. Table 2 shows the summary of the observed absolute gravity values at the four stations. It is clear that the standard deviation for all the set gravity is less than $1.2 \mu$ gal. Figure 2 depicts the corresponding set gravity distribution at the four stations. Table 3 lists the auxiliary information for coordinates of the four stations and the geophysical corrections. In all, about 10000 drops, or 100 sets of gravity measurements were made; the observation accuracy 
Table 1. Gradient measured by LCR-G581 and LCR-G854.

\begin{tabular}{l|cccc}
\hline & Midu & Dali & Eryuan & Jianchuan \\
\hline Mean gravity difference ( $\mu$ gal) & -0.3394 & -0.2916 & -0.3138 & -0.3659 \\
Height $(\mathbf{c m})$ & 128.5 & 122.4 & 125.0 & 135.0 \\
Gradient $\left(\boldsymbol{\mu g a l ~ \mathbf { ~ m } ^ { - 1 } )}\right.$ & -2.64 & -2.38 & -2.51 & -2.71 \\
\hline
\end{tabular}

Table 2. Summary of the observed absolute gravity values $(130 \mathrm{~cm}$ above ground $)$ at the four stations.

\begin{tabular}{|c|c|c|c|c|}
\hline Date (2005) & Site & Gravity Value ( $\mu$ gal) & Drop & SD ( $\mu$ gal) \\
\hline 3 - 5 September & Midu & $978394738.5 \pm 0.1$ & 9267 & 1.2 \\
\hline $6-8$ September & Dali & $978346489.6 \pm 0.1$ & 8751 & 1.0 \\
\hline 9 - 11 September & Eryuan & $978327741.1 \pm 0.2$ & 4541 & 1.1 \\
\hline $11-13$ September & Jianchuan & $978317085.6 \pm 0.1$ & 9984 & 1.0 \\
\hline
\end{tabular}

(a) Sets

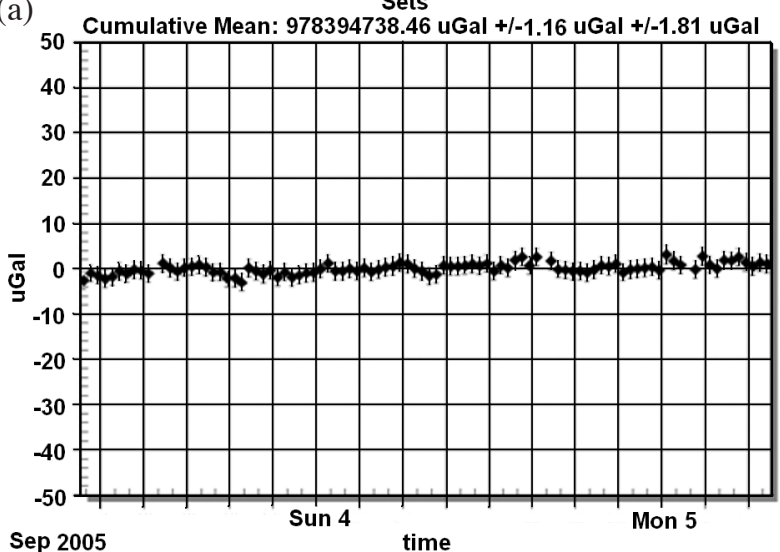

(c) Sets

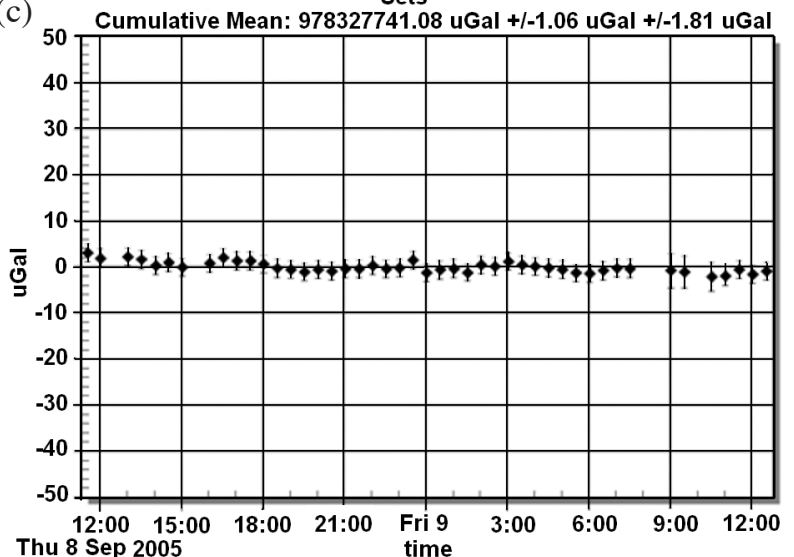

(b)

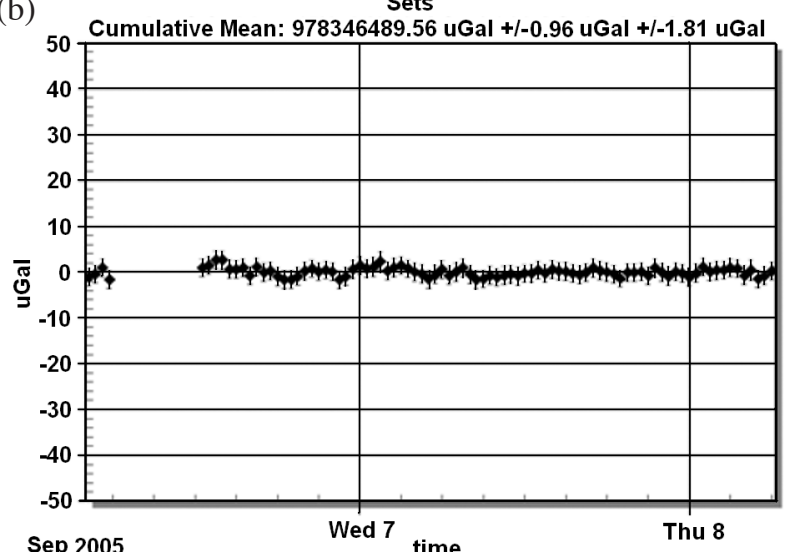

(d) Sets

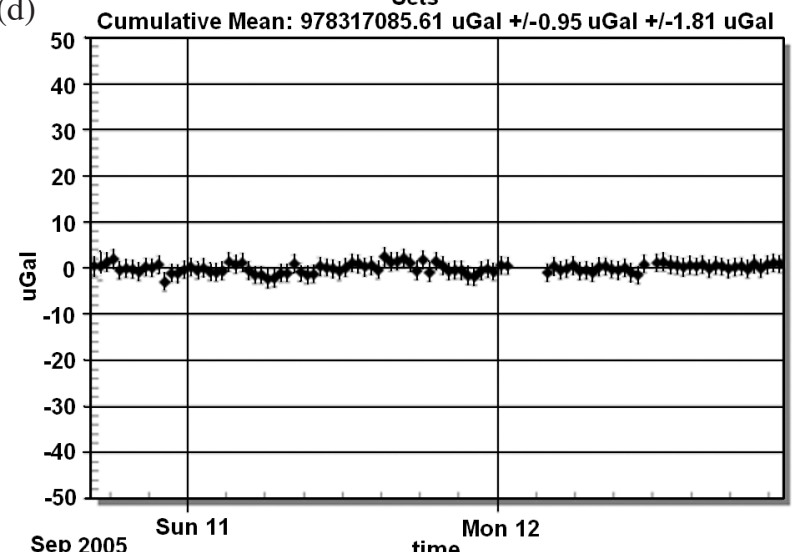

Fig. 2. Absolute gravity results (set gravity) observed in September 2005 at (a) Midu, (b) Dali, (c) Eryuan, and (d) Jianchuan. 
Table 3. Auxiliary information of station coordinates and geophysical corrections.

\begin{tabular}{l|l}
\hline Coordinates of stations & $\begin{array}{l}\text { Midu: } 25.3514^{\circ} \mathrm{N}, 100.4928^{\circ} \mathrm{E}, 1680 \mathrm{~m} \\
\text { Dali: } 25.6093^{\circ} \mathrm{N}, 100.2546^{\circ} \mathrm{E}, 1958 \mathrm{~m} \\
\text { Eryuan: } 26.1008^{\circ} \mathrm{N}, 99.9476^{\circ} \mathrm{E}, 2120 \mathrm{~m} \\
\text { Jianchuan: } 26.5378^{\circ} \mathrm{N}, 99.8963^{\circ} \mathrm{E}, 2230 \mathrm{~m}\end{array}$ \\
$\begin{array}{l}130.0 \mathrm{~cm} \text { above ground } \\
\text { Gravity in Table } 2\end{array}$ & $1.000-1.162$ (depends on tidal component) \\
Tidal factors & $0.3 \mu \mathrm{gal} \mathrm{hPa}^{-1}$ \\
Pressure correction & IERS Bulletin B, $\delta$ - factor $=1.164$ \\
Polar motion correction & ETGTAB (11 components), final effect is less than $0.1 \mu \mathrm{gal}$ \\
Ocean loading correction & "g" V5 \\
\hline
\end{tabular}

was good. The standard deviation of the final gravity set was less than $1.0 \mu \mathrm{gal}$.

\subsection{Relative Gravity Measurements}

At the time of the measurement of absolute gravity, the relative gravity measurement was also performed at the 40 points (Fig. 1) simultaneously, using the five gravimeters as mentioned above. The combined measurement by using absolute and relative instruments is called "hybrid gravity measurement." Since the gravity network is controlled by absolute gravity stations, all gravity values at the relative points can be transformed to absolute gravity. Therefore, the whole gravity network can be considered as an absolute gravity network. Including the gravity results measured at the four absolute gravity stations and the 40 relative points, the final gravity values of the network are listed in Table 4. Generally, the gravity is less in the north area than that in the south region due to the higher topographical height in the north. The preliminary gravity results serve as a reference for gravity changes through repeat measurements in the future. As an example, the gravity value at Dali station is used in the following discussions.

The Olivia and g-soft programs are used in data processing; some physical corrections were made to compensate for earth tides, ocean loading, and polar motion. All gravity values are transformed from the observation point at $1.3 \mathrm{~m}$ height from the ground. Final results show negative gravity change rates of $-1.97 \pm 0.66,-1.42 \pm 0.38$, and -0.41 $\pm 0.24 \mu \mathrm{gal} \mathrm{yr}^{-1}$, for the Lhasa, Kunming, and Dali stations, respectively. The rate of change is obtained using a leastsquares fit. The effects of an annual or seasonal signal are assumed to be reduced by averaging data over a long period of time. The same reasoning applies for the loading corrections from snow accumulation and melting, hydrology, and the atmosphere.

\section{VERTICAL DISPLACEMENTS OF THE TIBETAN PLATEAU AND CORRECTIONS TO THE GRAV- ITY CHANGE RATE}

We use GPS data at the three stations to obtain the vertical displacement rate. Since the early 1990s, several GPS networks for tectonic studies have been established in China and neighboring regions (Abdrakhmatov et al. 1996; Bilham et al. 1997; King et al. 1997; Zhu et al. 1997; Larson et al. 1999; Bendick et al. 2000; Chen et al. 2000; Shen et al. 2000; Wang et al. 2001). Most importantly, 25 permanent GPS stations have been established and continuous observations have been made to the present day (Gan et al. 2007) The Lhasa, Kunming, and Dali stations belong to parts of the permanent network where we have high-quality data. Here we use GIPSY software to reduce phase and pseudo-orange data at a site position. The GPS data collected at ca. 20 IGS stations throughout Asia and 18 continuous sites within China are organized into discrete $24 \mathrm{~h}$ segments and are processed simultaneously to yield a daily network solution. The precise satellite orbit and clock are fixed to the non-fiducial products provided by the JPL (Heflin et al. 1992). We solve clock biases, and atmospheric refraction per site with loose constraints in 3D coordinates. Phase ambiguities are also estimated, but no ambiguity resolution was done; phase ambiguities are estimated as real numbers and not fixed to integers. We apply azimuth and elevation-dependent antenna phase center models, following the tables recommended by IGS. We select a subset of IGS sites with a longer time span for definition a reference frame, and rotate the loosely constrained daily solutions onto the ITRF2000 (Altamimi et al. 2002) by seven-parameter similarity transformation. We then obtain a time series of vertical components for each site. The time series is then fit with a weighted least-squares sense to a linear function that includes the initial coordinate and the secular motion rate. Furthermore, assuming a time series characterized by a white noise process, we derive a 
Table 4. Gravity values (mgal on ground) measured in the gravity network in the Dali county area.

\begin{tabular}{|c|c|c|c|c|c|c|c|}
\hline \multicolumn{2}{|c|}{ Profile 1} & \multicolumn{2}{|c|}{ Profile 2} & \multicolumn{2}{|c|}{ Profile 3} & \multicolumn{2}{|c|}{ Profile 4} \\
\hline Jianchuan & 978317.438 & Eryuan & 978328.067 & Dali & 978346.799 & Midu & 978395.082 \\
\hline 01 & 978280.526 & 11 & 978379.834 & 21 & 978449.569 & 31 & 978313.800 \\
\hline 02 & 978270.636 & 12 & 978324.201 & 22 & 978413.265 & 32 & 978342.240 \\
\hline 03 & 978236.737 & 13 & 978240.525 & 23 & 978364.190 & 33 & 978382.193 \\
\hline 04 & 978303.347 & 14 & 978312.934 & 24 & 978337.870 & 34 & 978328.198 \\
\hline 05 & 978289.556 & 15 & 978343.799 & 25 & 978347.786 & 35 & 978232.915 \\
\hline 06 & 978293.853 & 16 & 978364.771 & 26 & 978348.198 & 36 & 978295.663 \\
\hline 07 & 978315.780 & 17 & 978309.767 & 27 & 978333.670 & 37 & 978386.838 \\
\hline 08 & 978243.502 & 18 & 978277.913 & 28 & 978307.901 & 38 & 978386.766 \\
\hline 09 & 978158.852 & 19 & 978276.153 & 29 & 978385.165 & 39 & 978334.334 \\
\hline 10 & 978324.461 & 20 & 978301.670 & 30 & 978439.245 & 40 & 978353.803 \\
\hline
\end{tabular}

post-fit RMS of $1.1-1.5 \mathrm{~mm}$ for the vertical component of site position and standard deviation of $<0.1 \mathrm{~mm} \mathrm{yr}^{-1}$ (1 sigma) for the vertical rate. The rate uncertainty might be overoptimistic because of neglect of the time-correlated noise inherited in the geodetic time series. The rate error might be underestimated by a factor of 5 - 11 if a pure white noise model is assumed for the coordinate time series (Mao et al. 1999). Zhang et al. (1997) found that the rate uncertainty might be $2-4$ times larger than that for fractional white noise and 3 - 6 for white plus flicker noises. We adopt a moderate scale factor of five because the time-correlation noise averaged down gradually over time. Multiplying the standard deviation of $0.1 \mathrm{~mm} \mathrm{yr}^{-1}$ by five engenders the rate uncertainty of ca. $0.5 \mathrm{~mm} \mathrm{yr}^{-1}$, which is comparable with a vertical rate precision of $0.4-0.6 \mathrm{~mm} \mathrm{yr}^{-1}$ assigned by Prawirodirdjo and Bock (2004) and Calais et al. (2006). Finally, the aggregate station coordinates of the three stations show that all three stations exhibit positive displacements vertically, implying that the Tibetan Plateau is continuing its uplift. The uplift rates for Lhasa, Kunming, and Dali are $+0.8 \pm 0.5,+2.3 \pm 0.5$ and $+0.5 \pm 0.5 \mathrm{~mm} \mathrm{yr}^{-1}$, respectively. Such a mean vertical displacement rate of $1.2 \mathrm{~mm} \mathrm{yr}^{-1}$ agrees well with the conclusion $\left(1.14 \mathrm{~mm} \mathrm{yr}^{-1}\right)$ obtained on a geological scale by Rowley and Currie (2006).

The observed gravity change rates $\mathrm{g}^{11}$ described above are presented in Table 5 . These gravity change rates are obtained on the deformed earth surface. They can therefore be decomposed into several contributions associated with crustal vertical displacement, surface denudation, GIA ef- fect, and internal mass change. We consider them separately to interpret the gravity changes. We first eliminate the contribution from the surface movement as determined by GPS. The gravity gradient for a mean spherical earth model is known to be $-3.08 \mu \mathrm{gal} \mathrm{cm}^{-1}$ (Heiskanen and Moritz 1967). This gradient applies for free air correction in case when the observation point moves vertically in space with no mass change. However, if the gravity measurement is performed on the deformed earth surface, the observation point moves together with the earth surface: the free air gradient is no longer applicable. Instead, the Bouguer gradient must be used. According to an earlier study (Heiskanen and Moritz 1967), the Bouguer correction can be estimated as $+1.1 \pm$ $0.1 \mu \mathrm{gal} \mathrm{cm} \mathrm{cm}^{-1}$ based on the local crustal density $\rho=2.7$. $2.9 \mathrm{~g} \mathrm{~cm}^{-3}$ (Chen and Yang 2004). Thus the Bouguer gradient is obtained as $-1.9 \mu \mathrm{gal} \mathrm{\textrm {cm } ^ { - 1 }}$. Multiplying the Bouguer gradient by the corresponding vertical displacements inferred from GPS measurements, we obtain the Bouguer gravity change rate corrections as $-0.16 \pm 0.02,-0.44 \pm 0.02$, and $-0.10 \pm 0.02 \mu \mathrm{gal} \mathrm{yr}^{-1}$ for the three stations, respectively $\left(\mathrm{g}^{2}\right)$ in Table 5).

Next, we consider the gravity rate of change contributed from the surface denudation of the Tibetan Plateau. Because of erosion, much mass is denuded from the mountains over the whole plateau and is subsequently transported by rivers into the Indian Ocean, the East China Sea, and adjacent basins (Westaway 1995). Most of the denudation is considered to happen below the observation points, this mass loss decreases the gravity and should 
Table 5. Gravity change rates at Lhasa, Kunming, and Dali stations, where $\mathrm{g}^{1)}$ is the observed gravity change rates; $\mathrm{g}^{2)}$ is the gravity rates by vertical displacement; $\mathrm{g}^{3)}$ indicates denudation-caused gravity change rate; $\mathrm{g}^{4)}$ is the GIA-induced gravity change rate; and $\mathrm{g}^{5)}=\mathrm{g}^{1)}-\mathrm{g}^{2)}-\mathrm{g}^{3)}-\mathrm{g}^{4)}$ (unit: $\mu$ gal $\mathrm{yr}^{-1}$ ).

\begin{tabular}{lccccc}
\hline Stations & $\mathbf{g}^{\mathbf{1}}$ & $\mathbf{g}^{\mathbf{2}}$ & $\mathbf{g}^{3)}$ & $\mathbf{g}^{\mathbf{4})}$ & $\mathbf{g}^{\mathbf{5}}$ \\
\hline Lhasa & $-1.97 \pm 0.66$ & $-0.16 \pm 0.1$ & $-0.25 \pm 0.1$ & $-0.25 \pm 0.2$ & $-1.31 \pm 0.70$ \\
Kunming & $-1.42 \pm 0.38$ & $-0.44 \pm 0.1$ & $-0.25 \pm 0.1$ & $-0.06 \pm 0.1$ & $-0.67 \pm 0.41$ \\
Dali & $-0.41 \pm 0.24$ & $-0.10 \pm 0.1$ & $-0.25 \pm 0.1$ & $-0.06 \pm 0.1$ & $-0.00 \pm 0.28$ \\
Mean & $-1.26 \pm 0.46$ & $-0.23 \pm 0.1$ & $-0.25 \pm 0.1$ & $-0.25 \pm 0.1$ & $-0.66 \pm 0.49$ \\
\hline
\end{tabular}

be evaluated. Westaway (1995) pointed out that the most concentrated denudation of the Tibetan Plateau occurs at its eastern and southeastern margins, within and around its Yunnan area. The combined sediment flux indicates an amount of $0.8 \mathrm{~km}^{3} \mathrm{yr}^{-1}$. The average denudation rate would be $1.5 \mathrm{~mm} \mathrm{yr}^{-1}$ if this denudation were to occur over the 600 $\times 800 \mathrm{~km}$ area for which the gravity measurements were carried out. That study also estimated that $0.4 \mathrm{~km}^{3} \mathrm{yr}^{-1}$ is eroded from the Himalayas and transported by rivers to the Indian Ocean and that $0.5 \mathrm{~km}^{3} \mathrm{yr}^{-1}$ is taken northward from Tibet. The equivalent loss rate of the mass layer is about $0.8 \mathrm{~mm} \mathrm{yr}^{-1}$ if $0.9 \mathrm{~km}^{3} \mathrm{yr}^{-1}$ erosion is assumed to occur over the entire Tibetan Plateau. Overall, the $2.3 \mathrm{~mm} \mathrm{yr}^{-1}$ denudation rate is an important factor of the gravity value reduction. This denudation rate has been confirmed by another independent study by Métivier et al. (1999) (Fig. 3), which estimated the total denudation amount of the Tibetan Plateau as $1.5 \mathrm{~km}^{3} \mathrm{yr}^{-1}$. Other studies (Lal et al. 2004) also found a high denudation rate of $2 \mathrm{~mm} \mathrm{yr}^{-1}$ in the Kunlun area and the Tibetan Plateau's eastern margin. Assuming $2.3 \mathrm{~mm} \mathrm{yr}^{-1}$ denudation as a simple Bouguer layer, its contribution to

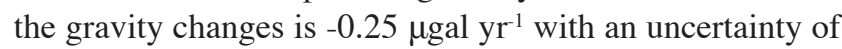
$\pm 0.1 \mu$ gal yr $^{-1}$. The resultant $\mathrm{g}^{3)}$ is listed in the fourth column in Table 5 .

\section{GRAVITY CHANGES OBSERVED BY GRACE}

In this section, we investigate the GRACE data in the Tibetan Plateau, to strengthen the correctness of surface observed gravity change rate. For this purpose, Sun et al. (2010) processed all the monthly GRACE data available from 2002 to 2009, provided by JPL (Jet Propulsion Laboratory), GFZ (GeoForschungsZentrum) and CSR (Center for Space Research) groups. The average monthly gravity changes are then smoothed by the Gaussian filter (radius is $400 \mathrm{~km}$ ), with each month's change refer to the mean value

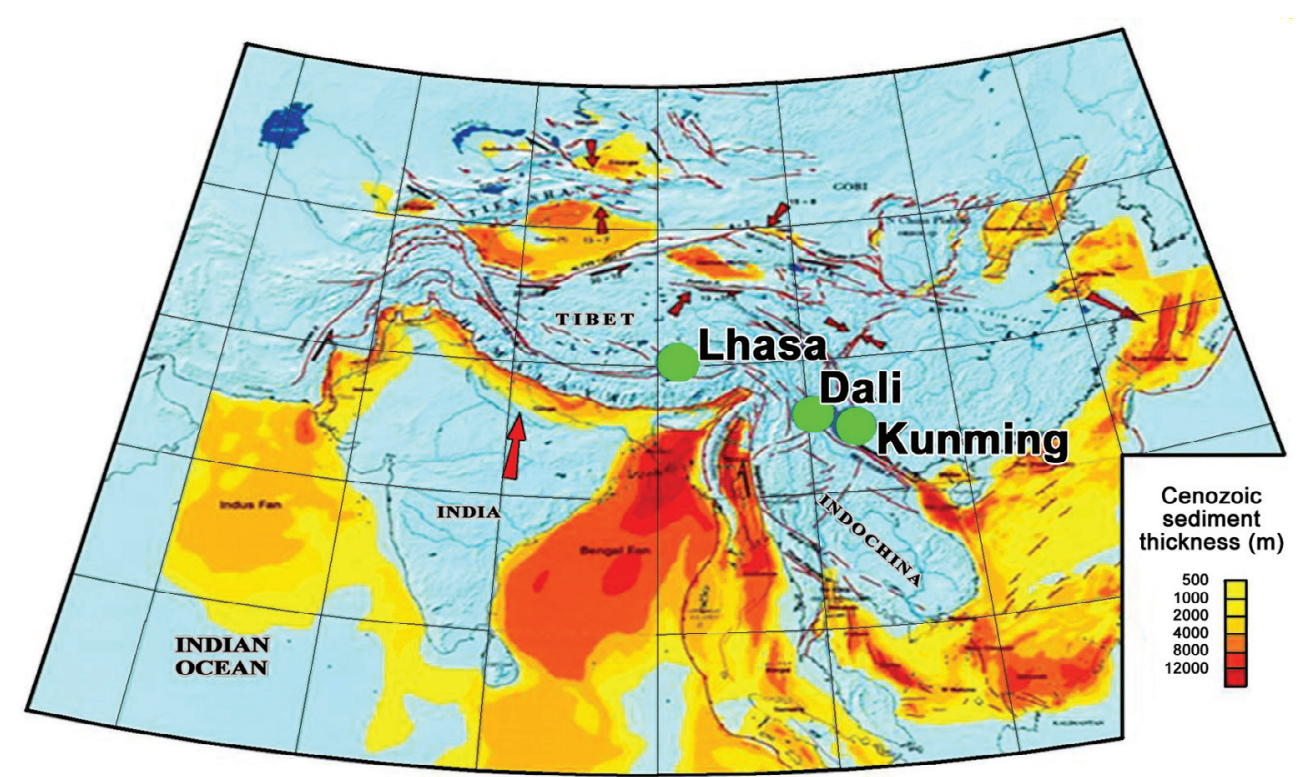

Fig. 3. Sedimentary thicknesses in Asia (after Métivier et al. 1999). The mass of sediment denudated from the Tibetan Plateau deduce the gravity at the three stations. 
of the whole 2002 - 2009 period. They found discernible annual changes at the southwestern boundary of China, surrounding the Tibetan Plateau. During the first half year (January - June), it shows negative gravity changes; in the last half year, it shows positive gravity changes. The annual change range is from -10 to $+10 \mu$ gal. That change is considered to result from precipitation and seasonal surface water storage changes in the area.

To observe how the three gravity stations discussed in this study affected by the annual change, they (Sun et al. 2010) computed the time series of gravity change at Lhasa station for two radius of Gaussian filters: 400 and $800 \mathrm{~km}$. Results show clearly annual changes; the changes are considered to result from precipitation and surface water storage changes. Although the magnitude is small, the Lhasa station is near the southwestern boundary of China. On the other hand, results show that the smaller the Gaussian filter radius, the larger the gravity variation magnitude. For the Gaussian radius of $400 \mathrm{~km}$, gravity varies about $\pm 5 \mu \mathrm{gal}$; for that of $800 \mathrm{~km}$, the gravity variation ranges $\pm 3 \mu \mathrm{gal}$. The gravity rate of change of the monthly gravity time series show that different Gaussian filter radii yield different linear fit results (annual gravity change rates) which imply that the gravity rate of change is Gaussian-radius dependent. For $R=400 \mathrm{~km}$, the gravity rate of change is $-0.58 \mu \mathrm{gal} \mathrm{yr}^{-1}$; for $R=800 \mathrm{~km}$, the gravity rate of change is $0.17 \mu \mathrm{gal} \mathrm{yr}^{-1}$.

The gravity change rates for Gaussian filters of 300 to $1000 \mathrm{~km}$ are computed and depicted in Fig. 4. It is readily apparent that the gravity rate increases (in absolute value) gradually as the Gaussian filter radius decreases, with the FG5 observed gravity rate of change as limit. This value is obtained from the FG5 measurement on the deformed earth surface described above, as corrected by the free-air gradient (Sun et al. 2009). It is therefore clear that the space and

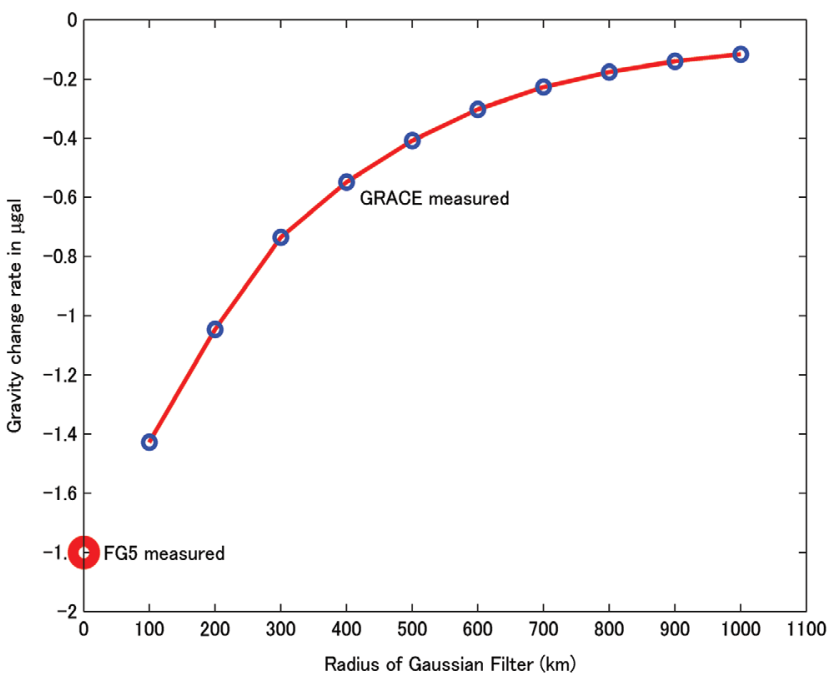

Fig. 4. Gravity change rate observed by GRACE with different radius of Gaussian filter and the FG5 observed one at Lhasa station. ground observed gravity change rates are harmonic and that they agree well.

It is noteworthy that the agreement of the gravity rate of change observed by ground and space measurements merely reveals that both measurements are consistent. The gravity rate of change signal reflects much physical information. However, it is difficult to separate these physical sources from GRACE and absolute gravity data. To identify each physical source, independent knowledge of ice, snow, and water is necessary. In a long-term view, the gravity rate of change caused by the precipitation and ice melt is considered small; seasonal variations in those parameters are smoothed out by averaging data over several years. Their contribution to the secular gravity rate of change correlates to the global water balance, which generally has a small change rate. The remaining GIA effects are considered nonnegligible and deserving of special discussion.

\section{GIA EFFECTS CONTRIBUTED IN THE SECULAR GRAVITY CHANGES}

A GIA effect is usually considered to result from three sources over time: the post-glacial rebound (PGR) caused by deglaciation of the last glacial maximum (LGM) about 21 thousand years ago, the little ice age (LIA) retreat of the last few hundred years, and present day ice melting (PDIM), which is currently ongoing. No ice model exists for LIA and PDIM in the Tibetan area. Therefore, it is difficult to evaluate and adjudge their contribution to the gravity rate of change. Actually, because the three gravity stations are far from the present ice covering area, According to the simulation study of Sun et al. (2010), the contribution from LIA and PDIM is expected to be small compared to that by LGM. Therefore, we only consider the GIA effect caused by the LGM below.

Wang (2001) and Kaufmann (2005) discussed GIA effects on vertical displacement and the gravity rate of change in the Tibetan area. Based on the ice model of Kuhle et al. (1990), Wang (2001) computed the GIA effects for four viscosity models. Kaufmann (2005) investigated GIA effects in three ice models: Kuhle, tibet4, and tibet6. He argued that gravity change from glacier isostatic adjustment can be

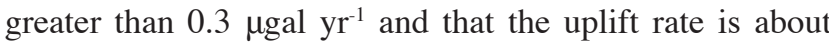
$3 \mathrm{~mm} \mathrm{yr}^{-1}$. However, in light of the above GPS data and geological rate (Rowley and Currie 2006), it seems that Wang (2001) and Kaufmann's (2005) results were overestimated. At least great uncertainty exists; their mutual comparison reveals that the uncertainty is about $100 \%$, fundamentally attributable to the inaccurate ice model. Taking into account the uncertainty and overestimated values, we apply the small number of the gravity change rates of model B in Fig. 5 in our current discussion, i.e., the GIA-induced gravity change rate $\mathrm{g}^{4)}$ at Lhasa $=-0.25 \mu \mathrm{gal} \mathrm{yr}^{-1}, \mathrm{Kunming}=-0.06 \mu \mathrm{gal} \mathrm{yr}^{-1}$, and Dali $=-0.08 \mu \mathrm{gal} \mathrm{yr}^{-1}$. The results are listed in Table 5 . 

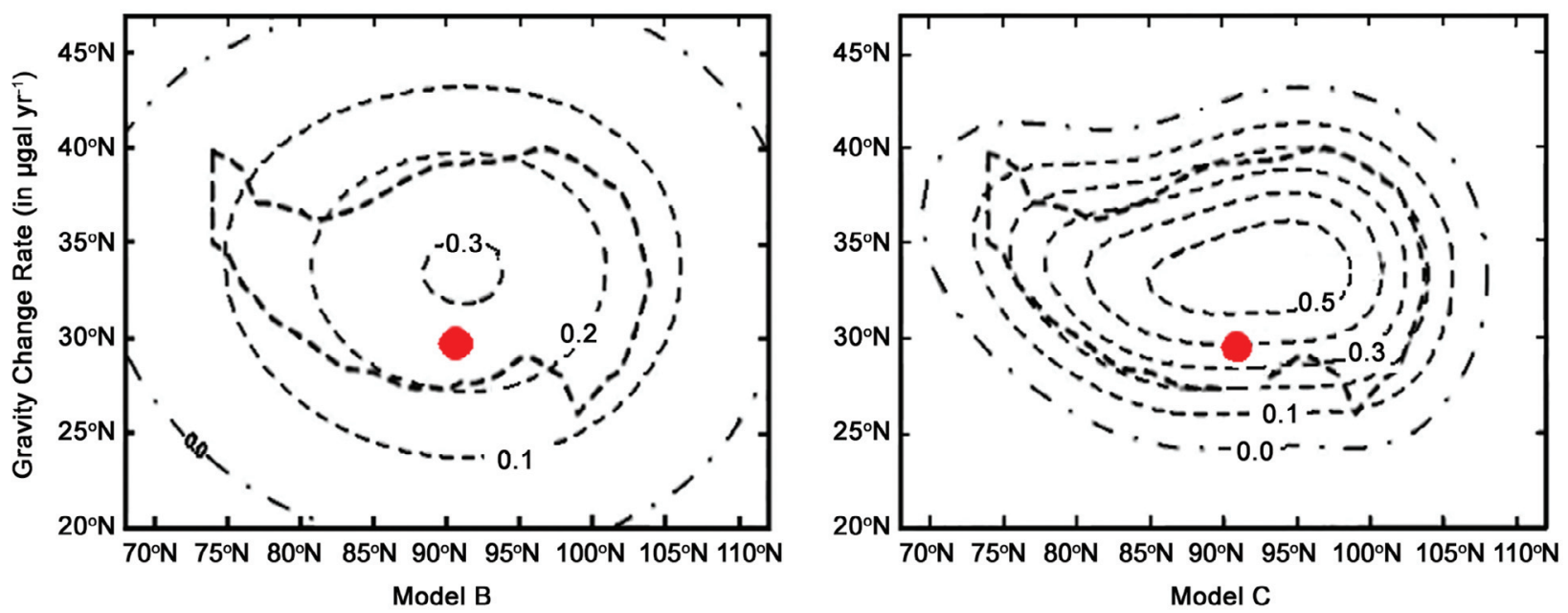

Fig. 5. GIA (LGM)-induced gravity change rate in the Tibetan Plateau (Wang 2001).

Subtracting the gravity changes attributable to the vertical displacement, denudation and GIA effect from the observed gravity changes rates, i.e., $g^{5)}=g^{1)}-g^{2)}-g^{3)}-g^{4)}$, we obtain the gravity change rates for the three stations as -1.31 $\pm 0.70,-0.67 \pm 0.41$, and $-0.00 \pm 0.28 \mu \mathrm{gal} \mathrm{yr}^{-1}$, respectively, which are free of crustal motion (Table 5). The final gravity change rates are attributed to the mass change beneath the observation points. The negative gravity changes suggest that the total mass under the observation stations is diminishing gradually. The mean gravity decline rate for the three stations is $-0.66 \pm 0.49 \mu \mathrm{gal} \mathrm{yr}^{-1}$.

\section{RESIDUAL GRAVITY CHANGE REVEALS IN- CREASING CRUSTAL THICKNESS}

Based on the physics of isostasy, some of the Indian subcontinent's lighter continental mass was subducted below the Asian continental mass before "locking up" and transmitting India's movement to the Asian crust. Consequently, the Asian crust was shortened and thickened by surface folding, large-scale overthrusting, and plastic flow at depth. The crust of the Tibetan Plateau thickened, thereby lifting up the crust surface. The bottom of the crust moves downward. Simultaneously, the plateau's area expands laterally, with its mass flowing sideward, due to the lateral pressure gradient within the lower crust that tend to drive material out from bottom regions that have thickened, as detected using the GPS measurements described above (Wang et al. 2001). According to the isostatic theory, the lower crust is usually sufficiently weak to be regarded as a fluid. Its flow is governed by variations in pressure at the base of the brittle layer. Subsequently, the heavier mantle is pushed sideward and the crustal bottom sinks. Gravity is not sensitive to the horizontal flow of mass. Therefore, the contribution to the gravity change is mainly attributable to vertical movement of the crust, including the surface and bottom of the crust. As a result, the gravity is expected to decrease, due to crustal thickening.

After removing the effect of crustal deformation on gravity change, the residual gravity change $-0.66 \pm 0.49$ $\mu$ gal $\mathrm{yr}^{-1}$ is attributed to lowering Moho at depth by crustal thickening. The additional crust on the crustal bottom is portrayed as a single layer with uniform thickness $h$. Assuming a crustal density of $2.6 \mathrm{~g} \mathrm{~cm}^{-3}$ and mantle density of $3.4 \mathrm{~g} \mathrm{~cm}^{-3}$ (Chen and Yang 2004), with density contrast of $\Delta \rho=0.8 \pm 0.2 \mathrm{~g} \mathrm{~cm}^{-3}$, the gravity change related to this Bouguer layer can be expressed simply as. The crustal expansion downward is inferred as $1.9 \pm 1.4 \mathrm{~cm} \mathrm{yr}^{-1}$. Compared to the mean surface uplift of $1.2 \mathrm{~mm} \mathrm{yr}^{-1}$ determined by GPS, this result seems to be reasonable in light of the mean elevation of $4.5 \mathrm{~km}$ of the Tibetan Plateau and the crustal thickness of $70 \mathrm{~km}$ below it.

\section{CONCLUSION}

Concluding the discussion presented above for all physical sources, results show that the gravity rate of change is mainly attributable to the tectonic deformation resulting from the collision between the Indian Plate and Eurasian Plate. Simultaneously, the surface displacement, surface erosion, and GIA effects are not negligible. Therefore, the discussion and conclusion presented in Sun et al. (2009) are fundamentally reasonable. The crustal thickness model is improved slightly after the GIA effect is considered.

Acknowledgements Helpful Comments by Dr. Prakash Kumar, and by reviewers Drs. Shuangxi Zhang and Ting Chen are highly appreciated. This study was financially supported by a Japanese JSPS research-in-add project and a "Thousand Person's Plan" supporting fund by Graduate University of Chinese Academy of Science. 


\section{REFERENCES}

Abdrakhmatov, K. Y., S. A. Aldazhanov, B. H. Hager, M. W. Hamburger, T. A. Herring, K. B. Kalabaev, V. I. Makarov, P. Molnar, S. V. Panasyuk, M. T. Prilepin, R. E. Reilinger, I. S. Sadybakasov, B. J. Souter, Y. A.Trapeznikov, V. Y. Tsurkov, and A. V. Zubovich, 1996: Relatively recent construction of the Tien Shan inferred from GPS measurements of present-day crustal deformation rates. Nature, 384, 450-453, doi : 10.1038/384450a0. [Link]

Altamimi, Z., P. Sillard, and C. Boucher, 2002: ITRF2000: A new release of the International Terrestrial Reference Frame for earth science applications. J. Geophys. Res., 107, 2214, doi: 10.1029/2001JB000561. [Link]

Bendick, R., R. Bilham, J. Freymueller, K. Larson, and G. Yin, 2000: Geodetic evidence for a low slip rate in the Altyn Tagh fault system. Nature, 404, 69-72, doi: 10.1038/35003555. [Link]

Bilham, R., K. Larson, J. Freymueller, 1997: GPS measurements of present-day convergence across the Nepal Himalaya. Nature, 386, 61-64, doi: 10.1038/386061a0. [Link]

Calais, E., J. Y. Han, C. DeMets, and J. M. Nocquet, 2006: Deformation of the North American plate interior from a decade of continuous GPS measurements. J. Geophys. Res., 111, B06402, doi: 10.1029/2005JB004253. [Link]

Chen, W. P. and Z. Yang, 2004: Earthquakes beneath the Himalayas and Tibet: Evidence for strong lithospheric mantle. Science, 304, 1949-1952, doi: 10.1126/science. 1097324. [Link]

Chen, Z., B. C. Burchfiel, Y. Liu, R. W. King, L. H. Royden, W. Tang, E. Wang, J. Zhao, and X. Zhang, 2000: Global Positioning System measurements from eastern Tibet and their implications for India/Eurasia intercontinental deformation. J. Geophys. Res., 105, 1621516227, doi: 10.1029/2000JB900092. [Link]

Gan, W., P. Zhang, Z. K. Shen, Z. Niu, M. Wang, Y. Wan, D. Zhou, and J. Cheng, 2007: Present-day crustal motion within the Tibetan Plateau inferred from GPS measurements. J. Geophys. Res., 112, B08416, doi: 10.1029/2005JB004120. [Link]

Heflin, M., W. Bertiger, G. Blewitt, A. Freedman, K. Hurst, S. Lichten, U. Lindqwister, Y. Vigue, F. Webb, T. Yunck, and J. Zumberge, 1992: Global geodesy using GPS without fiducial sites. Geophys. Res. Lett., 19, 131-134, doi: 10.1029/91GL02933. [Link]

Heiskanen, W. A. and H. Moritz, 1967: Physical Geodesy. W. H. Freeman \& Co Ltd., 364 pp.

Kaufmann, G., 2005: Geodetic signatures of a Late Pleistocene Tibetan ice sheet. J. Geodyn., 39, 111-125, doi: 10.1016/j.jog.2004.08.005. [Link]

King, R. W., F. Shen, B. C. Burchfiel, L. H. Royden, E.
Wang, Z. Chen, Y. Liu, X. Y. Zhang, J. X. Zhao, and Y. Li, 1997: Geodetic measurement of crustal motion in Southwest China. Geology, 25, 179 - 182, doi: 10.1130/ 0091-7613(1997)025<0179:GMOCMI>2.3.CO;2. [Link]

Kuhle, M., 1990: New data on the Pleistocene glacial cover of the southern border of Tibet: The glaciation of the Kangchendzönga Massif (8585 m, E-Himalaya). GeoJournal, 20, 415-421, doi: 10.1007/BF00174983. [Link]

Lal, D., N. B. W. Harris, K. K. Sharma, Z. Gu, L. Ding, T. Liu, W. Dong, M. W. Caffee, and A. J. T., Jull, 2004: Erosion history of the Tibetan Plateau since the last interglacial: Constraints from the first studies of cosmogenic ${ }^{10} \mathrm{Be}$ from Tibetan bedrock. Earth Planet. Sci. Lett., 217, 33-42, doi: 10.1016/S0012821X(03)00600-9. [Link]

Larson, K. M., R. Bürgmann, R. Bilham, and J. T. Freymueller, 1999: Kinematics of the India-Eurasia collision zone from GPS measurements. J. Geophys. Res., 104, 1077-1093, doi: 10.1029/1998JB900043. [Link]

Mäkinen, J., H. Virtanen, Q. X. Qiu, and L. R. Gu, 1993: The Sino-Finnish Absolute Gravity Compaign in 1990. Publications of the Finnish Geodetic Institute, 116, 7-49.

Mao, A., C. G. A. Harrison, and T. H. Dixon, 1999: Noise in GPS coordinate time series. J. Geophys. Res., 104, 2797-2816, doi: 10.1029/1998JB900033. [Link]

Métivier, F., Y. Gaudemer, P. Tapponnier, and M. Klein, 1999: Mass accumulation rates in Asia during the Cenozoic. Geophys. J. Int., 137, 280-318, doi: 10.1046/ j.1365-246X.1999.00802.x. [Link]

Prawirodirdjo, L. and Y. Bock, 2004: Instantaneous global plate motion model from 12 years of continuous GPS observations. J. Geophys. Res., 109, B08405, doi: 10. 1029/2003JB002944. [Link]

Rowley, D. B. and B. S. Currie, 2006: Palaeo-altimetry of the late Eocene to Miocene Lunpola basin, central Tibet. Nature, 439, 677-681, doi: 10.1038/nature04506. [Link]

Shen, Z. K., C. Zhao, A. Yin, Y. Li, D. D. Jackson, P. Fang, and D. Dong, 2000: Contemporary crustal deformation in east Asia constrained by Global Positioning System measurements. J. Geophys. Res., 105, 5721-5734, doi: 10.1029/1999JB900391. [Link]

Sun, W., Q. Wang, H. Li, Y. Wang, S. Okubo, D. Shao, D. Liu, and G. Fu, 2009: Gravity and GPS measurements reveal mass loss beneath the Tibetan Plateau: Geodetic evidence of increasing crustal thickness. Geophys. Res. Lett., 36, L02303, doi: 10.1029/2008GL036512. [Link]

Sun, W., T. Hasegawa, X. Zhang, Y. Fukuda, C. K. Shum, and L. Wang, 2011: Simulation of Gaussian filter applied in processing GRACE data - Gravity rate of 
change at Lhasa, Tibet. Sci. China Ser. D, in press.

Takemoto, S., Y. Fukuda, T. Higashi, I. Kimura, Y. Hiraoka, Y. Hiyama, H. Nakagawa, M. Honda, T. Tanaka, H. Aoki, M. Hashizume, H. Amemiya, A. Suzuki, H. P. Sun, Y. Wang, H. Xu, Y. Zhu, W. Zhang, J. J. F. Hunag, T. K. Yeh, H. Yu, C. Hwang, S. Dwipa, D. S. Kusuma, P. Manurung, T. C. Hua, M. Y. B. A. Bakar, S. H. Tahir, K. Wattanaikorn, R. M. Agaton, and E. Macaspac, 2006: Establishment of an absolute gravity network in East- and Southeast-Asia. J. Geodetic Soc. Jpn., 52, 51-95.

Tapponnier, P., Z. Xu, F. Roger, B. Meyer, N. Arnaud, G. Wittlinger, and Y. Jingsui, 2001: Oblique stepwise rise and growth of the Tibet Plateau. Science, 294, 16711677, doi: 10.1126/science.105978. [Link]

Wang, H., 2001: Effects of glacial isostatic adjustment since the late Pleistocene on the uplift of the Tibetan Plateau. Geophys. J. Int., 144, 448-458, doi: 10.1046/j.1365-24 6x.2001.00340.x. [Link]

Wang, Q., P. Z. Zhang, J. T. Freymueller, R. Bilham, K. M. Larson, X. Lai, X. You, Z. Niu, J. Wu, Y. Li, J. Liu, Z. Yang, and Q. Chen, 2001: Present-day crustal deformation in China constrained by Global Positioning System measurements. Science, 294, 574-577, doi: 10.1126/science.1063647. [Link]

Wang, Y. and W. Zhang, 2004: Absolute gravity measurement in Chinese continent and its application to geodynamics. Progress in Geodesy and Geodynamics, Hubei
Science \& Technology Press, 96-102. (in Chinese) Wang, Y., W. Zhang, J. G. Zhan, X. H. Hao, H. B. Wang, and H. Z. Xu, 2004: Gravity change detected by repeated absolute gravity measurements in the western Yunnan and Lhasa, China and its implication. Chin. J. Geophys., 47, 95-100.

Westaway, R., 1995: Crustal volume balance during the India-Eurasia collision and altitude of the Tibetan plateau: A working hypothesis. J. Geophys. Res., 100, 15173-15192, doi: 10.1029/95JB01310. [Link]

Zhang, J., Y. Bock, H. Johnson, P. Fang, S. Williams, J. Genrich, S. Wdowinski, and J. Behr, 1997: Southern California permanent GPS geodetic array: Error analysis of daily position estimates and site velocities. J. Geophys.Res., 102, 18035-18055, doi: 10.1029/97JB01380. [Link]

Zhang, W. and Y. Wang, 2005: Effect of water level variations of Erhai Lake on absolute gravity observation at Xiaguan fiducial station. J. Geodesy Geodyn., 25, 114116.

Zhang, W., Y. Wang, H. Xu, C. Zhang, X. Hao, and M. Liu, 2001: Test of the uplift of Tibetan plateau by FG5 absolute gravimeter at Lhasa Station. Chi. Sci. Bull., 46, 256-258.

Zhu, W., Z. Cheng, Y. Xong, H. Xu, and L. Huang, 1997: Preliminery results of crustal deformation in the Tibetan Plateau using GPS observation. Sci. China D, 27, 385 . 